\title{
Motivational Preconditions of Specialist Leadership Development in the Process of Training
}

\author{
Sergii Boltivets \\ State Institute of Family and Youth Policy of Ukraine \\ Mykola Korolchuk \\ Kyiv National University of Trade and Economics \\ Valentyna Korolchuk \\ Kyiv National University of Trade and Economics \\ Yurii Ivanov \\ National Academy of Security Service of Ukraine \\ Vitalii Chornyi \\ National Defence University of Ukraine Named After Ivan Cherniakhovskyi
}

The article focuses on the issue of motivational preconditions of leadership development in the process of professional training. The article presents theoretical and empirical results of the study of professional motives formation peculiarities that influence optimization of students' leadership qualities in the conditions of an educational process and discusses innovative motivational and leadership approaches to become a professional. The authors made emphasis on the fact that the activity is multimotivated and encouraged by a group of conscious and unconscious motives. In the empirical study, the authors found that leadership is determined by certain motivational prerequisites, which, in particular, combine the need for success, recognition, respect, and power. Motivation for success is formed on their basis, in the process of professional training. Future specialists are optimized for leadership potential as evidenced by their level of communicational and organizational skills development. It was substantiated that educational training projects for students should be included in the educational process. Also, the stages of professional motivation formation were determined.

Keywords: professional motives, educational process, motivation formation, leadership potential

\section{INTRODUCTION}

Under the conditions of information society's rapid development and dynamic changes in economic and political processes, specialists with a high level of professional motivation and leadership skills are competitive and successful. The combination of these psychological phenomena forms a new creative 
motivational and leadership approach for becoming a professional which meets the modern requirements of the state functioning. Modernization of the education system through innovative development with the implementation of such an approach will determine both the effectiveness of professional training of highly qualified personnel and the further successful development of the country.

Becoming a professional, forming the necessary leadership skills, professional competence, and interest in the activity necessary for successful work in modern society begins from the moment of the desire to master the profession. It is conditioned by the further development of motivation to work in a certain field. Lack of motivation for activity, insufficient level of professional motives development impedes effective mastery of the profession and formation of leadership qualities, leads to loss of desire to be better, to be a leader, to motivate by own example and so on. It is impossible to work successfully without a motivation for work because only then a person becomes a professional in his or her business when he has an interest in it, a desire to bring something new, original. To be not only a model for imitation but also a leader in a certain team or sphere of activity. Therefore, the problem of researching motivational prerequisites for the development of specialist leadership in the process of vocational training becomes urgent.

Within these issues, the theoretical tendencies of scientists deserve special attention. Realization of these tendencies is a basis for new directions of motivational research for the development of personality leadership qualities. First of all, I. Mostovicz, analyzing the data of domestic and foreign psychology, concluded that there are three main approaches to studying the motivation of activity in psychology. According to the first of them, the motivation for work is connected with emotional states, the second cognitive formations, and the third - connection of cognitive and emotional processes. Therefore, motives have a structure that characterizes the connection of three aspects: cognitive, emotional, and motor. Reviewing motivational theories, E. Fisher noted that they fall into two groups: content theories that reveal motivational aspects and process theories that reveal the link between need, behavior, and reward.

The fundamentals of motives in the formation of certain behavior and the effect of factors on motivation are discussed in the work of R. Gopal \& R. Chowdhury, which, in particular, consider practical ways of realizing a leader's motivational potential. In addition, scholars have emphasized that motivation is an important component of business success and prosperity in the current dynamic and competitive market. M. Almansour noted that among all the functions performed by a manager, employee motivation is the most important and challenging task. It is much more difficult for a leader to motivate a team than to motivate an individual member, as people in the team have different beliefs, values, goals, and expectations. Therefore, to motivate the team effectively, it is advisable to choose a single motivational strategy. If leaders cannot motivate a team, they are unlikely to succeed.

In general, leadership is a multifaceted process connected with a certain purpose, motivating others to act, and motivation to the achievement of professional goals. Considering different leadership styles, modern scholars prefer a dynamic leadership style within effective motivation. This is when the manager is energetic enough, adjusts to the team, and shows kindness, inspiring with own example of successful actions. Dynamic leaders objectively evaluate the work of the team as a whole and the contribution of each employee individually, they are attentive, fair, and humble managers. These characteristics help to motivate the whole team, not just individual members.

Instead, authoritarian leaders are distant from their team, for the most part, they do not motivate, but merely give guidance, make decisions individually, and set the rules imposing them on employees. This leadership style does not contribute to the development of creativity and personality of professionals, it can be relevant only under the conditions of urgency and time constraint to perform a specific task when you need to quickly perform the job. In contrast to the authoritarian leadership style, there is a democratic one that is considered to be effective. This style reflects such principles and processes as self-determination and equal participation of all team members. Democratic leaders foster collective decision-making by engaging their staff and offering them support and choice. This style, in contrast to the authoritarian style, is characterized by cooperation, active participation of all team members in discussing issues and determining ways to implement them.

Analysis of the research indicates increased attention of scientists to professional motivation and motivational aspects of leadership. The available scientific works are mainly of a general psychological 
nature within the framework of consideration of motivational theories, which do not reveal the essence of motivation for acting as an important prerequisite for the development of specialist leadership or focus on leadership as a style of leadership within which staff motivation should take place. Thus, the authors are aiming to highlight the motivational prerequisites for the development of specialist leadership in the process of vocational training.

\section{MATERIALS AND METHODS}

In order to find out the motivational preconditions for the development of leadership in the process of vocational training during 2018-2019, we conducted a psychodiagnostic study of students of different courses at one of the leading institutions. The method of study was chosen as a slice method because it involves the organization of psychological search as a separate, time-limited, fixed for the moment of existence of a certain phenomenon or process, cognitive interaction with the subject of study. In addition, an ascertaining experiment was performed that was consistent with the procedure and aimed at obtaining empirical sections on the subject of cognition.

Since the motivation to work is manifested, first of all, in the process of accomplishing the tasks, the future specialist should accordingly be oriented towards the achievement of a professional goal and in general the success in the activity. Otherwise, he will perform the task in any way or as it turns out and without interest as a result, which will not subsequently contribute to the development of his professional skill, leadership, and moral satisfaction. Therefore, it is appropriate to determine whether in the process of training based on the needs identified above the motivation for success. To do this, we use the Ehlers' Motivation for Success method, which gives an opportunity to evaluate the desire to achieve the goal, to success, which leads to the development of a specialist's ability to overcome obstacles, achieve high performance in professional activity, successfully compete with others, etc.

The study was conducted using a set of psychodiagnostic methods: "Communicative and organizational skills" (KOZ), "Motivators of social and psychological activity of the individual", "Motivation for success" according to Ehlers. It covered 250 respondents (50 students from each course of study. The results of the survey, with $95 \%$ probability characterize the general population (determined the sample size for a share, due to the margin of error formula). The sample structure (by student distribution according to the course of study) closely reflects the structure of the general population. Such organization and research procedure gave a possibility to obtain information on structural and dynamic changes in the period of professional training in motivation for the activity of specialists and to identify its features as an important precondition for leadership development.

\section{RESULTS AND DISCUSSION}

\section{The Features of the Motivational Preconditions of Leadership}

Today, one of the important characteristics of a modern specialist is leadership. On the one hand, it determines individual professional development because of the desire of the individual for the primacy. On the other, it allows to win the trust in a certain team, to promote the organization of successful activity, by own example to motivate colleagues for quality work and to unite them to achieve constructive goals. In the process of professional development, we can observe the transformation of the motivational sphere of personality. As we know, activity is polymotivated and triggered by a group of motives that are placed in a particular hierarchy (depending on their importance to the specialist).

Motivation for activity is, on the one hand, a hierarchy of professional motives, and on the other, the process of formation and actualization of motives. First of all, it should be noted that the motive is a rather complex psychological phenomenon that has not only a multilevel structure but also an integrated mechanism of formation. It forms a more complex personal structure - motivation. Motivation as a process is determined by a large number of factors and is the driving force of the individual, which determines the development of his professionally important qualities, including leadership. The list of the latter includes, first of all, communicative and organizational abilities of a specialist, since they are one of the important 
prerequisites for establishing a constructive functioning of any social group. Well organized process of communication with colleagues is the key to the success of the team because communication not only shapes moral and psychological climate but also characterizes the leader's ability to clearly formulate professional tasks. Precise organization of work depends on the peculiarities of its implementation and awareness of the action's algorithm of each team member. In addition, a specialist with advanced leadership qualities is distinguished by such motive as a desire for success which determines the tendency foundations for the qualitative realization of professional goals.

Motives are formed according to the prevailing needs of the individual, it is important to identify the dominant needs that determine the desire for recognition and respect in a particular social group, ability to organize the work of the team, and so on. Due to the close connection of needs and motives, their identification does not follow, but the sequence of their reflection in the personality consciousness is clearly traced - conscious needs become motives that should be classified according to types depending on the goals that the personality sets, not the source of origin. The activity of a specialist is polymotivated and triggered by a group of motives that are placed in a certain hierarchy depending on their importance in a particular situation and in the whole process of work. Internal promptings (conscious, unconscious) to action should be understood under the motives of the individual. Main motives mainly include desire, interests, beliefs, aspirations, ideals.

As for the direct motivational preconditions for the development of specialists leadership qualities, they are based on the above theoretical bases and begin to form in the process of professional training which should be aimed at the development of the personal component (psychological characteristics, among which leadership is distinguished as an important precondition for successful functioning in modern society) and system of attitudes (motives, views, outlook, etc.) to learn the future work. Using the methodology "Communicative and organizational skills" to determine the level of development of communicative $(\mathrm{C})$ and organizational $(\mathrm{O})$ abilities of students from the first to fifth courses of study, we calculated their respective coefficients (Table 1).

The indicators presented in the table show that in the process of vocational training there is a positive dynamic of the development of communication and organizational abilities of students. Thus, the high level of organizational abilities development is typical for the students of the fourth year of studying, and communicative abilities for the third and fourth years of studying. During the fifth year of studying students have a very high level of development of both organizational and communication skills. In addition, the available significant differences in the obtained indicators show that from the second year of studying students become more organized and have an average level of development of communicative characteristics. Motives depend on the prevailing needs of the individual in the process of distinguishing the motivational preconditions for leadership, it is important to identify the dominant needs. They were investigated according to the "Methodology of diagnostics of motivators of social and psychological activity of the individual", the main among which are: 1 - the need to succeed; 2 - the need for power; 3 the need for recognition, respect (the tendency to affiliation). 
TABLE 1

INDICATORS OF THE RESULTS OF STUDENTS' SURVEY BY THE METHOD OF KOZ

\begin{tabular}{|l|c|c|c|c|}
\hline \multirow{2}{*}{ Scales/Training period } & \multicolumn{2}{|c|}{$\begin{array}{c}\text { Organizational } \\
\text { ability }\end{array}$} & \multicolumn{2}{c|}{$\begin{array}{c}\text { Communicative } \\
\text { ability }\end{array}$} \\
\cline { 2 - 5 } & $\begin{array}{c}\text { Coefficient } \\
\mathbf{M} \pm \mathbf{m}\end{array}$ & $\begin{array}{c}\text { Scale of } \\
\text { points }\end{array}$ & $\begin{array}{c}\text { Coefficient } \\
\mathbf{M} \pm \mathbf{m}\end{array}$ & $\begin{array}{c}\text { Scale of } \\
\text { points }\end{array}$ \\
\hline 1 year of studying & $0.52+0.04$ & 1 & $0.46+0.02$ & 2 \\
\hline 2 years of studying & $0.68+0.03^{*}$ & 3 & $0.61+0.05^{*}$ & 3 \\
\hline 3 years of studying & $0.69+0.03$ & 3 & $0.71+0.03^{*}$ & 4 \\
\hline 4 years of studying & $0.71+0.04$ & 4 & $0.72+0.03$ & 4 \\
\hline 5 years of studying & $0.89+0.03^{*}$ & 5 & $0.78+0.05^{*}$ & 5 \\
\hline
\end{tabular}

Note: $\mathbf{M}$ is the arithmetic mean; $\mathbf{m}$ is a statistical error of the arithmetic mean; ${ }^{*}-$ the level of reliability of differences in the dynamics of students' educational activity ( $p<0.05)$; rating scale: 1 - low, 2 - below average, 3 - medium, 4 - high, 5 - very high.

The maximum number of points that assesses the need is 25 . Levels of need: low -7 points or less; average $-8-18$ points; high -19 points or more. The following average parameters and statistical error of expressing the stated needs for students in each of the courses of study are:

- for the 1st year: $1-20.78 \pm 0.36 ; 2-18.69 \pm 0.40 ; 3-18.35 \pm 0.34$;

- for the 2nd year: $1-20.99 \pm 0.25 ; 2-18.28 \pm 0.25^{*} ; 3-18.11 \pm 0.27 *$;

- for the 3rd year: $1-20.07 \pm 0.31 ; 2-19.35 \pm 0.31 * ; 3-19.48 \pm 0.28 *$;

- for the 4th year: $1-21.27 \pm 0.35 ; 2-17.65 \pm 0.45^{*} ; 3-18.18 \pm 0.35$;

- for the 5th year: $1-21.29 \pm 0.26 ; 2-18.30 \pm 0.45 ; 3-18.96 \pm 0.26$.

We found out that there are no significant differences between the expressive needs of first- and secondyear students. At the same time, for other courses, the differences between the average expressiveness of future specialist's need for power and the need for recognition of each course of studying with the next course $\left({ }^{*} \mathrm{p} \leq\right.$ $0.05)$ were revealed. Between the second and third courses, the significance of differences in the manifestation of the need for power is defined at the level of $t=2.70$; the significance of the differences is $p=0.0075$; between the third and fourth courses $-t=3.22 ; p=0.0016$; between fourth and fifth courses $-t=2.39 ; p=0.0179$. There were also statistically significant differences in need for recognition between second- and third-year students $(\mathrm{t}=$ $3.43 ; \mathrm{p}=0.0007)$, third- and fourth-year students $(\mathrm{t}=2.81 ; \mathrm{p}=0.0057)$.

In addition, with an accuracy of $\mathrm{p} \leq 0.03$, we proved that $83 \%$ of students have a high level of need to succeed. $87 \%$ of students are most likely to see this indicator in the fifth year of study, and $80 \%$ of the respondents in the first and second years, $85 \%$ in the third, and $84 \%$ in the fourth year. Next in importance is the need for group recognition and respect that was expressed in $56 \%$ of students. The lowest number of such students are in the fourth and second years of studying, respectively $49 \%$ and $48 \%$. In the fifth year of studying $59 \%$ of future professionals need recognition and respect, and $56 \%$ in the first year. The most pronounced need for recognition and respect is observed in the third year $-67 \%$. Work with them can be arranged precisely through the realization of this need, that is, through respect and approval of educational achievements. Difficult "grinding" of characters, establishing new contacts, fighting for social position on the course and the group took place on the previous courses, so there is a desire to be respected, valued, as they are already on the verge of transition to senior courses. In the fourth year of studying most students, compared to other courses, show a high level of need for power $-63 \%$, since during this period students want to be independent and manage the situation. Most students have too high a level of self-confidence and confidence in their peremptory correctness.

Thus, we found out that the most expressed motivation for success is typical for the students of the first year, their indicator is $21.42 \pm 2.29$ points, which according to the interpretative criteria of the methodology is regarded as too high (21 points and more). At the higher-than-average level (17-20 points) this indicator is determined for bachelors (fourth year) $-20.71 \pm 2.42$ points, practically at the border of high level - for 
masters (fifth year) $-19.21 \pm 2.95$, but lower than for the first-year students and bachelors $(\mathrm{p}<0.05)$. It was found that in the process of vocational training there is a motivation for success, which has certain peculiarities, namely: its level is too high for freshmen (first year of studying), it is too high for bachelors, and high for masters. That is, freshmen are mostly too ambitious, still have youthful maximalism, and are focused only on purpose, without taking into account certain social factors. And by the fifth year, students have a constructive behavioral strategy to achieve their professional goals.

In general, obtained empirical indicators show that: leadership is determined by certain motivational preconditions, which, in particular, combine the need to succeed, to be recognized, to be respected, in power, and motivation to succeed. In the course of professional training future specialists are optimized for leadership potential, as evidenced by their inherent level of development of communication and organizational skills.

\section{Development of Professional Motivation That Determines the Specialist's Leadership}

In modern conditions, professional training for successful work should represent not only a purposeful process of acquiring professional competence but also the development of motivation for activity, which is an important prerequisite for the formation of leadership qualities of a specialist in an educational institution. The theoretical-empirical analysis made it possible to substantiate and establish the substantive components of the motivational prerequisites for the development of individual leadership and to find out that it is formed under the influence of such motives as the desire for success, recognition, and power, not for the satisfaction of their ambitions, but for constructive cooperation, to achieve professional goals. Thus, professional motivation is changed during the professional training. This development has two directions: first, the very motives for the activity are changed; second, as the level of professionalization changes, the motivational preconditions for leadership also change.

The process of professional motivation can be represented as a chain of connected components, namely: need (as impulse, reason) - motive (interest, desire, conviction, desire, ideal) or complex of motives - goal (one common or set of goals) - actions aimed at satisfaction needs and the realization of the motive (achievement of the goal) - the result. Therefore, motivation is the process of creating a motive that begins with a need, and the goal determines the action-realization of that motive to get a certain result. Motivation acts as a multifunctional determinant of the formation of a specialist's leadership potential. It encourages and regulates the activity. Therefore, the main functions of motivation for professional activity are the following:

- motivating function actualizes the intentions of the individual to perform a specific type of activity and activates certain behavior regarding its implementation;

- organizational function identifies possible ways of action for the realization of actual motives and achievement of relevant professional goals;

- regulatory function determines the necessary behavior, activates and directs certain actions necessary for meeting the needs and realization of urgent motives;

- corrective function provides optimality of actions and, if necessary, their change, depending on the level of significance of the motive relevant for the specialist.

This gives a possibility to define motivation of a specialist to professional activity as a process of motives formation depending on individual-psychological characteristics and level of professional training, under the influence of factors (external and internal; positive and negative) which activate, regulate, and direct behavior to conscientious and qualitative performance of professional tasks. So that the basic principles of motivation for professional activity which have become the preconditions for the leadership of a specialist to be further developed and have a constructive practical realization, students should be included in the system of educational training projects. They should be directed to preparing students for solving complex managerial professional tasks based on the integration of the acquired knowledge and formed leadership skills.

Within this, a training program on the topic: "Motivation of the staff for successful leadership" is relevant and effective. Its purpose is the formation of the motives of specialists for successful professional activity and motivational strategies of leadership. Forms of work are psychodiagnosis, motivational discourses, presentation 
workshops, group discussions, brainstorming, case method, business games. The main content modules of the proposed program are the following:

- organizational-theoretical - the adoption of principles and rules of group work, familiarization of the training participants with the principles and patterns of the motivational sphere development, his leadership potential; clarification of theoretical and applied aspects of motivation for successful work and development of leadership qualities; characterization of methods of motivation for successful work; analysis of the psychological mechanism of professional motivation formation, which determines the development of leadership potential;

- diagnostic and search - establishing motivational preconditions for successful activity of a specialist, his current motives for work and leadership qualities; determination of priority motives for work; diagnostic techniques that can be used in the process of interpersonal communication to determine the motives for professional activity of a specialist and leadership potential of a person;

- determination-basic - actualization of motives important for successful work and leadership; realization of the psychological mechanism of formation of necessary motive and leadership qualities; introduction of peculiarities of using effective methods of specialist motivation taking into account his individual-psychological features; development of complex professional motives and skills; development of leadership potential; use of motivational strategies in the process of management;

- $\quad$ presentation-action - presentation of basics of formation of motivational strategies of leadership and professional longevity; working out of methods motivational tendencies in the process of professional activity realization; presentation of complex methods for motivation of personnel to successful work and development leadership qualities; demonstration of the use of methods of formation of motives for leadership in specific situations; taking into account the personal characteristics of a specialist when choosing the best methods for forming professional motives and motivational preconditions for leadership;

- summing-perspective - analysis of achievements and possibilities for their application in the process, singling out ways to optimize motivational priorities and strategies of leadership personnel discussing the prospects and directions of specialists' self-motivation in certain professional areas.

Such educational training projects implemented in the framework of vocational training will constructively influence the student's personality by forming certain internal beliefs, outlook, intellectual and individualpsychological characteristics, motives for certain actions, development of leadership potential, and motivation for a particular type of activity. In general, such motivation is determined by professional competencies and individual-psychological features of future specialists; learning conditions and innovations, requirements of the profession to personality.

\section{CONCLUSION}

Thus, we found out that motivation is an important precondition for the development of leadership of a future specialist in the professional training process. The considerations based on the theoretical foundations of the motivational preconditions of specialist leadership and the results of empirical research within the framework of these problems have become the basis for determining the following stages of professional motivation formation: stage of influence; stage of awareness; stage of formation; stage of action; stage of result. We distinguished the following psychological indicators during the empirical study of the motivational preconditions for the development of specialist leadership in the process of vocational training:

- In the process of studying there is a tendency for students to increase the level of development of organizational and communication skills depending on the year of studying. By the fifth year of studying these important components of leadership have the highest level of development, which is the key to further successful professional activity. 
- Depending on the year of studying, students express changes in the need for self-affirmation. It is the most pronounced in the third year and the least in the fourth. In addition, students of all years of studying strive for success, and the level of expression of their needs in power and recognition changes as they transit from year to year. It is more pronounced for third-year students.

- The high level of motivation for success, which is typical for all years of studying students, forms the effective prerequisites for optimizing the motivational indicators of a specialist's leadership; first-year students have an excessive desire to obtain a successful result before graduation it is stabilized and has a high level; specialists, with such a level of motivation for success, tend to focus on their strength, flexibly and persistently achieve their goal.

Thus, the motivational preconditions for specialist leadership are formed in the process of vocational training and represent a complex of interrelated elements, namely: the need for success, recognition, respect, and power; based on the motivation for success, which leads to optimization of leadership potential, based on communication and organizational skills. Further intensive innovative development of motivational and leadership strategies of the future specialist, their active use in the activity, is possible under the condition of preliminary development of practical skills, skills, and optimal styles of professional interaction by involving students in educational training programs. Within the framework of the considered motivational and leadership approach for becoming a professional, it is advisable to concentrate attention on the development of professional motivation and formation of leadership potential which will further ensure competitiveness in the modern labor market and promote the economic development of the state.

\section{REFERENCES}

Almansour, M. (2012). The Relationship Between Leadership Styles and Motivation of Managers Conceptual Framework. Journal of Arts, Science and Commerce, 3(1), 161.

Clark, R. (2013). Research-Tested Team Motivation Strategies. Performance Improvement, 44(1), 13.

Enbom, J., Gustafsson, S., \& Larsson, A. (2005). How Coaches Motivate Teams? Retrieved April 24, 2020, from http://www.diva-portal.org/smash/get/diva2:1024333/FULLTEXT01.pdf

Fisher, E. (2009). Motivation and Leadership in Social Work Management: A Review of Theories and Related Studies. Administration in Social Work, 33(4), 347.

Giltinane, C. (2013). Leadership styles and theories. Nursing Standard, 27(41), 35.

Gopal, R., \& Chowdhury, R. (2014). Leadership Styles and Employee Motivation: An Empirical Investigation in a Leading Oil Company. International Journal of Research in Business Management, 2(5), 1.

Herasymenko, S., Holovach, A., Erina, A. (2000). Statistika. KNUTE, Kyiv.

Ivanova, N. (2013). Formation of Motivation Fades to The Extreme in Extreme Minds. Problems of Extreme and Crisis Psychology, 3, 129.

Korolchuk, M.S., \& Krajnyuk, V.M. (2012). Theory and Practice of Professional Psychological Expulsion. Nika-Centr, Kyiv.

Lee, Y-J., \& Chang, W-Y. (2014). Effects of Teacher Training and Teaching Quality on Learning Satisfaction. Journal of Environmental Protection and Ecology, 15, 1472-1481.

Mostovicz, I. (2009). A Dynamic Theory of Leadership Development. Leadership and Organization Development Journal, 30(6), 563.

Naumenko, M.V., Rogov, E.I., \& Rogova, E.E. (2020). The relationship of leadership qualities and professional ideas among teachers of the additional education system. International Journal of Learning and Change, 12(1), 76-90.

Schaffer, B. (2008). Leadership and motivation. Super Vision, 69(2), 6.

Wiesenthal, A., Kalpna, J., Mcdowell, T., \& Radin, J. (2015). The New Physician Leaders: Leadership for A Dynamic Health. The New England Journal of Medicine, 3, 1.

Zhang, G-Q., \& Chen, C. (2021). An Empirical Study on the R $\{\backslash \&\}$ D Capability of EntrepreneurshipOriented Enterprises Based on the Mediating Effect of Industry-University Collaboration. Journal of the Balkan Tribological Association, 27(3), 466-478. 